\title{
PENGEMBANGAN USAHA KUE RUMAHAN UTI PALEMBANG MELALUI PENERAPAN MARKETING MIX DAN DOKUMEN BISNIS
}

\section{Palembang “Uti” Home Cake Business Development by Applying Marketing Mix and Business Documents}

\author{
Neneng Miskiyah, Mariskha Z, Purwati, Yulia Pebrianti \\ Jurusan Administrasi Bisnis, Politeknik Negeri Sriwijaya, Palembang
}

Article history

Received: Nev 29, 2020;

Accepted: Feb 3, 2021

* Corresponding author:

E-mail:

mariskha@polsri.ac.id

DOI: https://doi.org/

10.46549/igkojei.v2i1.166

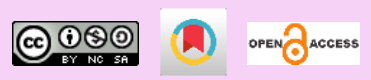

\begin{abstract}
Working as a housewife is a job that all women can do. However, being a housewife and an entrepreneur at the same time can only be done by certain women, like our current partner. Nursiati is a housewife and at the same time, she opens a home cake business that she has been doing for 12 years under the name Uti Home Cake Business. Uti Home Cake Business provides various types of cakes and street snacks. Every day, Uti's home cake business regularly provides 6 types of street snacks and cakes specially ordered by customers. Customers come from various circles and different places in Palembang city, such as the surrounding community, foundations, schools, and government and private agencies. In carrying out its business, our partner does not have business documents and finds it difficult when they are asked for business documents such as notes, receipts, and business stamps. Our partner also never make promotions. Customers know the partner's pastry business by word of mouth. The partner's turnover has increased, but the increase in profit is not too high nor constant. The purpose of this community service is that the partner can apply the marketing mix properly to maximize the profit. The results obtained from this activity are our partner now has business documents, product packaging designs, brochures, and the Instagram Online application $(I G)$ for promotion purposes.
\end{abstract}

Keywords: Marketing Mix; Business Documents; Social Media; Home Industry

\section{ABSTRAK}

Pekerjaan sebagai ibu rumah tangga adalah merupakan pekerjaan yang dapat dilakukan oleh semua kalangan wanita. Namun menjadi seorang ibu rumah tangga sekaligus berwirausaha hanya dapat dilakukan oleh kalangan wanita tertentu saja. Seperti mitra kami saat ini ibu Nursiati adalah seorang ibu rumah tangga sekaligus membuka usaha kue rumahan yang telah ditekuninya sejak 12 tahun yang lalu dengan nama usaha Kue Rumahan Uti. Usaha kue rumahan Uti menyediakan berbagai macam jenis kue basah dan jajanan pasar. Setiap hari usaha kue rumahan Uti menyediakan kue secara rutin sebanyak 6 macam jenis kue atau jajanan pasar dan kue yang dipesan khusus oleh pelanggan. Pelanggan datang dari berbagai kalangan dan tempat yang berbeda di kota Palembang, seperti masyarakat sekitar, yayasan, sekolah, dan instansi pemerintah maupun swasta. Dalam melaksanakan usahanya, mitra tidak memiliki dokumen bisnis dan kesulitan jika diminta dokumen bisnis seperti nota, kuitansi, dan cap usaha, dan mitra juga tidak pernah melakukan promosi. Pelanggan mengetahui usaha kue mitra dari mulut ke mulut. Omzet mitra mengalami peningkatan, akan tetapi peningkatan keuntungan tidak terlalu tinggi dan bahkan tetap. Tujuan dari pengabdian kepada masyarakat ini adalah mitra dapat menerapkan marketing mix sebagaimana mestinya sehingga keuntungan yang dicapai lebih maksimal. Hasil yang diperoleh dari kegiatan ini, 
mitra memiliki dokumen bisnis, desain kemasan produk, brosur, dan aplikasi Online Instagram (Ig).

Kata kunci: Marketing Mix; Dokumen Bisnis; Media Sosial; Home Industri

\section{PENDAHULUAN}

Emansipasi wanita sudah dimulai sejak usaha_R.A. Kartini agar wanita-wanita Indonesia menjadi wanita yang kuat dan dapat membantu perekonomian keluarga. Oleh karena itu saat ini telah banyak wanita-wanita yang bekerja, dan berusaha di ekonomi kecil dan mikro termasuk usaha rumah tangga. Kegiatan usaha produktif yang dapat menambah penghasilan keluarga dengan memanfaatkan kemampuan yang dimiliki serta modal yang sedikit namun dapat digunakan sebagai usaha (Widiastuti dkk, 2018). Mitra kami Usaha Kue Rumahan Uti adalah contoh usaha yang dirintis Ibu Nursiati 12 tahun yang lalu, yang menjual kue-kue basah dan jajanan pasar. Awalnya ibu Nursiati memulai usahanya dengan menjual lontong dan nasi gemuk. Namun usaha terus berkembang dengan menjual jajanan pasar dan kue basah kemudian dilanjutkan dengan memasak pada acara-acara sedekahan. Keterbatasan modal dan bertambahnya usia menyebabkan ibu Nursiati akhirnya menekuni usaha kue rumahan yang diberi nama Usaha Kue Rumahan Uti. Pembuatan kue dilakukan setiap hari, karena ibu Nursiati telah memiliki banyak pelanggan dan pemesan dari kalangan yang berbeda-beda karena promosi dari pelanggan lainnya. Pelanggan yang berasal dari lembaga resmi membutuhkan dokumen bisnis seperti nota, kuitansi, dan cap sebagai bukti transaksi penjualan. Mitra kami, tidak memahami sehingga belum bisa menyediakan dokumen bisnis yang diperlukan tersebut. Mitra kami murni menjalankan usaha bisnisnya secara langsung tanpa melalui media sosial yang akhir-akhir ini memberikan peluang pengembangan bisnis rumahan. Usaha mitra kami kue rumahan Uti ini berada di Jl. Sosial Lr. Keluarga 2 No. 421 Palembang. Gambar 1 adalah contoh jajanan kue yang dijual oleh mitra kami.
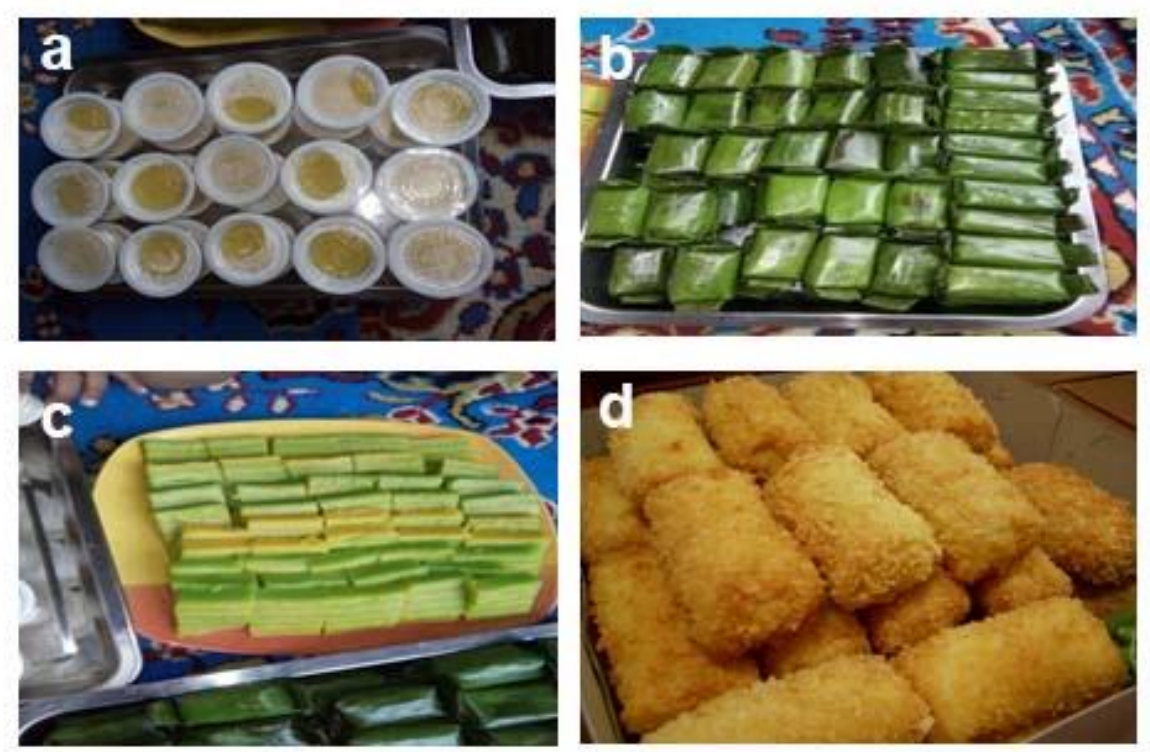


\section{Gambar 1. Macam kue yang dijual mitra. (a) Kue Puding Jagung; (b) Kue Lemper; (c) Kue Lapis Labu Parang; (d) Kue Risoles}

Pemasaran menurut Kotler dan Keller (2012) adalah suatu proses sosial dan manajerial yang didalamnya individu dan kelompok mendapatkan apa yang mereka butuhkan dan inginkan dengan menciptakan, menawarkan dan mempertukarkan produk dengan pihak lain. Teori pemasaran yang amat sederhana pun selalu menekankan bahwa dalam kegiatan pemasaran harus jelas siapa yang menjual, apa, dimana, bagaimana, bilamana, dalam jumlah berapa dan kepada siapa. Adanya strategi yang tepat akan sangat mendukung kegiatan pemasaran secara keseluruhan. Definisi ini menjelaskan bahwa pemasaran merupakan proses kegiatan usaha untuk melaksanakan rencana strategis yang mengarah pada pemenuhan kebutuhan konsumen melalui pertukaran dengan pihak lain. Berdasarkan definisi pemasaran tersebut dapat diketahui bahwa pemasaran terdiri atas beberapa unsur yang dapat diharapkan mampu meningkatkan penjualan suatu usaha.

Dalam suatu bisnis baik kecil maupun besar diperlukan adanya suatu dokumen bisnis atau surat bisnis yang dapat dijadikan sebagai bukti otentik dari suatu kegiatan bisnis yaitu antara penjual dan pembeli. Surat bisnis masih sangat diperlukan karena catatan tertulis tidak akan pernah terganti oleh komunikasi lisan, meskipun berkembang pesat dokumentasi lisan dengan memori storage dalam sistem komputerisasi (Finoza, 2009). Dokumen bisnis dapat berupa surat-surat bisnis, nota bisnis dan kuitansi. Selain itu diperlukan adanya legalitas usaha seperti cap usaha atau perusahaan, baik itu perusahaan besar maupun kecil.

Adapun permasalahan yang dihadapi mitra dalam kegiatan pengabdian ini adalah:

1. Permasalahan Marketing Mix terutama permasalahan pemasaran dan distribusi.

2. Mitra tidak memiliki dokumen bisnis dalam menjalankan usahanya.

Oleh karena itu, kegiatan pengabdian kepada masyarakat ini bertujuan untuk membantu mengatasi permasalahan mitra baik dalam bidang marketing mix maupun permasalahan dokumen bisnis.

\section{METODE}

Kegiatan pengabdian kepada masyarakat dilaksanakan di tempat Usaha kue rumahan Uti yang berada di J1. Sosial Lr. Keluarga 2 No. 421 Palembang oleh tim pelaksana yang terdiri dari 4 (empat) orang. Pelaksanaan aktivitas pengabdian kepada masyarakat ini didahului dengan sosialisasi sebagai upaya pendekatan antara pelaksana dengan pengusaha dengan harapan akan terjalin hubungan kerjasama yang baik untuk meningkatkan keuntungan usaha tersebut.

Kemudian Tim akan memberikan penjelasan mengenai marketing mix dan penerapannya dalam usaha Kue Rumahan Uti baik dengan cara memberikan penjelasan mengenai teori dasar pemasaran dan marketing mix maupun membantu bagaimana menerapkan marketing mix dalam usaha tersebut. 
Setelah itu Tim pelaksana kegiatan pengabdian juga memberikan penjelasan mengenai dokumendokumen yang diperlukan dalam usaha Kue Rumahan Uti. Menjelaskan pentingnya dokumen bisnis dalam sebuah usaha dan membantu mitra dalam pengadaan dokumen bisnis dalam rangka untuk meningkatkan kelancaran dalam transaksi bisnis maka dibutuhkan dokumen-dokumen bisnis seperti nota, kuitansi, dan cap usaha.

\section{HASIL DAN PEMBAHASAN}

Pelaksanaan kegiatan pengabdian ini bermaksud untuk menyelesaikan permasalahan marketing mix. Dalam kunjungan ke mitra, Tim melakukan diskusi dengan memberikan pemahaman mengenai marketing mix dan penerapannya dalam usaha Kue Rumahan Uti. Tim juga memberikan penjelasan mengenai teori dasar pemasaran dan marketing mix. Untuk meningkatkan penjualan, di dalam ilmu pemasaran dikenal istilah bauran pemasaran (marketing mix). Menurut Kotler dan Amstrong (2009), Marketing Mix adalah sekumpulan variabel-variabel pemasaran yang digunakan oleh perusahaan untuk mengejar target penjualan yang diinginkan. Jadi dapat disimpulkan bahwa marketing mix merupakan strategi pemasaran yang dilaksanakan secara terpadu atau strategi pemasaran yang dilakukan secara bersamaan. Strategi tersebut digunakan dengan menerapkan elemen strategi yang ada dalam marketing mix itu sendiri. Marketing mix yang biasa disebut sebagai 4P terdiri dari: Product, yaitu produk atau jasa yang dihasilkan haruslah memiliki kualitas dan keunikan yang mampu meningkatkan daya saing produk atau jasa tersebut di pasaran; $\underline{\text { Price }}$, yaitu harga yang dimaksud adalah sejumlah uang yang harus dibayar oleh konsumen untuk mendapatkan produk. Dengan kata lain, seseorang akan membeli barang jika pengorbanan yang dikeluarkan (yaitu uang dan waktu) sesuai dengan manfaat yang ia ingin dapatkan dari produksi barang atau jasa yang ditawarkan oleh perusahaan; $\underline{\text { Place }}$, yaitu saluran distribusi yang tepat juga menentukan berhasil tidaknya strategi pemasaran. Oleh karena itu, saluran distribusi menempati posisi yang krusial dalam marketing mix. Adapun definisi dari saluran distribusi ini sendiri adalah berbagai kegiatan atau upaya apapun yang dilakukan oleh perusahaan untuk membuat produk atau jasanya mudah diperoleh atau tersedia di tangan konsumen maupun pelanggannya; Promotion, yaitu sebuah upaya persuasi (bujukan atau dorongan) untuk mengajak para konsumen maupun calon konsumen untuk membeli (atau menggunakan) produk maupun jasa yang dihasilkan oleh suatu perusahaan.

Strategi ini dapat menjadi kesatuan yang luar biasa bermanfaat bagi bisnis, apabila pengusaha dapat menjalankan keseluruhan teknik marketing mix tanpa terkecuali dan juga memiliki tingkat kontinuitas pelaksanaan yang baik. Tim menjelaskan bahwa pemasaran itu adalah suatu sistem keseluruhan dari kegiatan bisnis yang ditujukan untuk merencanakan, menentukan harga, mempromosikan dan mendistribusikan barang dan jasa yang memuaskan kebutuhan, baik kepada pembeli yang ada maupun kepada pembeli potensial. Jadi pemasaran ini adalah sebuah proses dalam 
memuaskan kebutuhan dan keinginan manusia. Untuk mencapai kebutuhan dan kepuasan konsumen tersebut mitra harus memperhatikan beberapa bauran pemasaran (marketing mix) yang terdiri dari:

a. Produk

Produk yang dihasilkan mitra merupakan produk makanan yang tidak tahan lama berupa kuekue rumahan. Sementara kue-kue rumahan memiliki pesaing yang banyak dikarenakan kue-kue tersebut banyak dijual di pasar. Oleh karena itu kepada mitra disarankan untuk memperhatikan kualitas produknya mulai dari rasa, aroma, dan warnanya. Jika konsumen merasa kecewa dengan produk yang dihasilkan mitra, konsumen tersebut akan mengurangi bahkan berhenti untuk memesan produk tersebut. Selain itu disarankan agar mitra lebih banyak belajar untuk inovasi produk, agar konsumen tidak merasa bosan dan yang perlu diperhatikan juga, sebaiknya mitra memiliki minimal 1 (satu) produk unggulan yang berbeda dari para pesaingnya. Seperti yang dikemukakan oleh Fitri, dkk (2020) mitra perlu senantiasa menjaga kelezatan dan kekhasan rasa produk makanan tersebut sehingga ada perbedaan dan tidak banyak dijumpai di tempat penjualan makanan lainnya.

b. Harga

Selain memperhatikan harga pesaing disarankan kepada mitra agar melakukan perhitungan harga dengan sebaik-baiknya sehingga mendapatkan keuntungan sesuai dengan yang diharapkan.

c. Promosi

Selama ini tidak ada promosi yang dilakukan mitra. Orang melakukan pemesanan kue atau makanan dari mitra berdasarkan informasi dari orang-orang yang pernah melakukan pemesanan sebelumnya. Dalam hal ini promosi sangat penting dilakukan dalam memperkenalkan produk yang ditawarkan kepada pembeli yang telah ada selama ini maupun kepada pembeli potensial. Promosi dapat dilakukan dengan menggunakan berbagai media baik media massa, media elektronik, brosur dan lain-lain. Promosi dapat juga dilakukan melalu media sosial. Sebenarnya media sosial untuk berwirausaha dengan basis teknologi sudah banyak sekali seperti facebook, Instagram, twitter dan lain-lain. Keuntungan usaha berbasis online dapat dilakukan dari rumah saja tanpa harus menyediakan tempat khusus seperti ruko yang membutuhkan biaya operasional cukup besar, selain itu memudahkan untuk berinteraksi antara produsen dan konsumen. Keuntungan lainnya konsumen dapat dengan mudah memilih barang yang diinginkan (Aziz dkk, 2020).

d. Distribusi

Selama ini pemesan dilakukan secara langsung ke tempat mitra untuk mengambil kue atau makanan lainnya. Namun sesekali mitra juga dapat mengantarkan pesanannya kepada pemesan. Konsumen akan membeli atau memesan kembali apabila mereka merasa puas. Mitra harus 
memperhatikan bagaimana proses pengiriman dan penyerahan barang pesanan. Mitra juga harus mampu memenuhi apa yang diinginkan konsumen sehingga konsumen tidak merasa kecewa. Dengan demikian hubungan konsumen dan produsen akan terjalin dengan baik dan kesinambungan pemesanan dapat terus dijaga.

Kegiatan berikutnya Tim membantu menerapkan Marketing Mix dengan membantu mendesain kemasan produk dan sistem pemasaran melalui brosur Gambar 2 dan aplikasi Online Instagram (Ig).

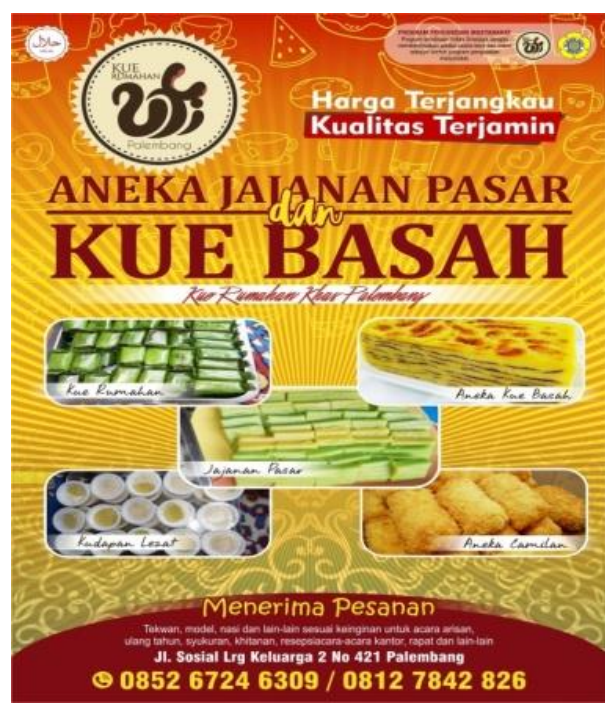

Gambar 2. Brosur untuk Mitra

Tim kemudian memberikan penjelasan mengenai dokumen-dokumen yang diperlukan dalam usaha Kue Rumahan Uti. Untuk meningkatkan kelancaran dalam transaksi bisnis maka dibutuhkan dokumen-dokumen bisnis seperti nota, kuitansi dan cap usaha. Tim juga menjelaskan pentingnya dokumen bisnis dalam sebuah usaha_karena merupakan bukti otentik transaksi yang dibutuhkan oleh konsumen. Oleh karena itu Tim memberikan penjelasan kepada Mitra mengenai pentingnya dokumen-dokumen tersebut dikarenakan dibutuhkan setiap kali melakukan transaksi sebagai bahan pertanggungjawaban pembelian barang. Oleh karena itu Tim membantu mitra dalam membuat dan mendesain dokumen bisnis seperti pada Gambar 3. 

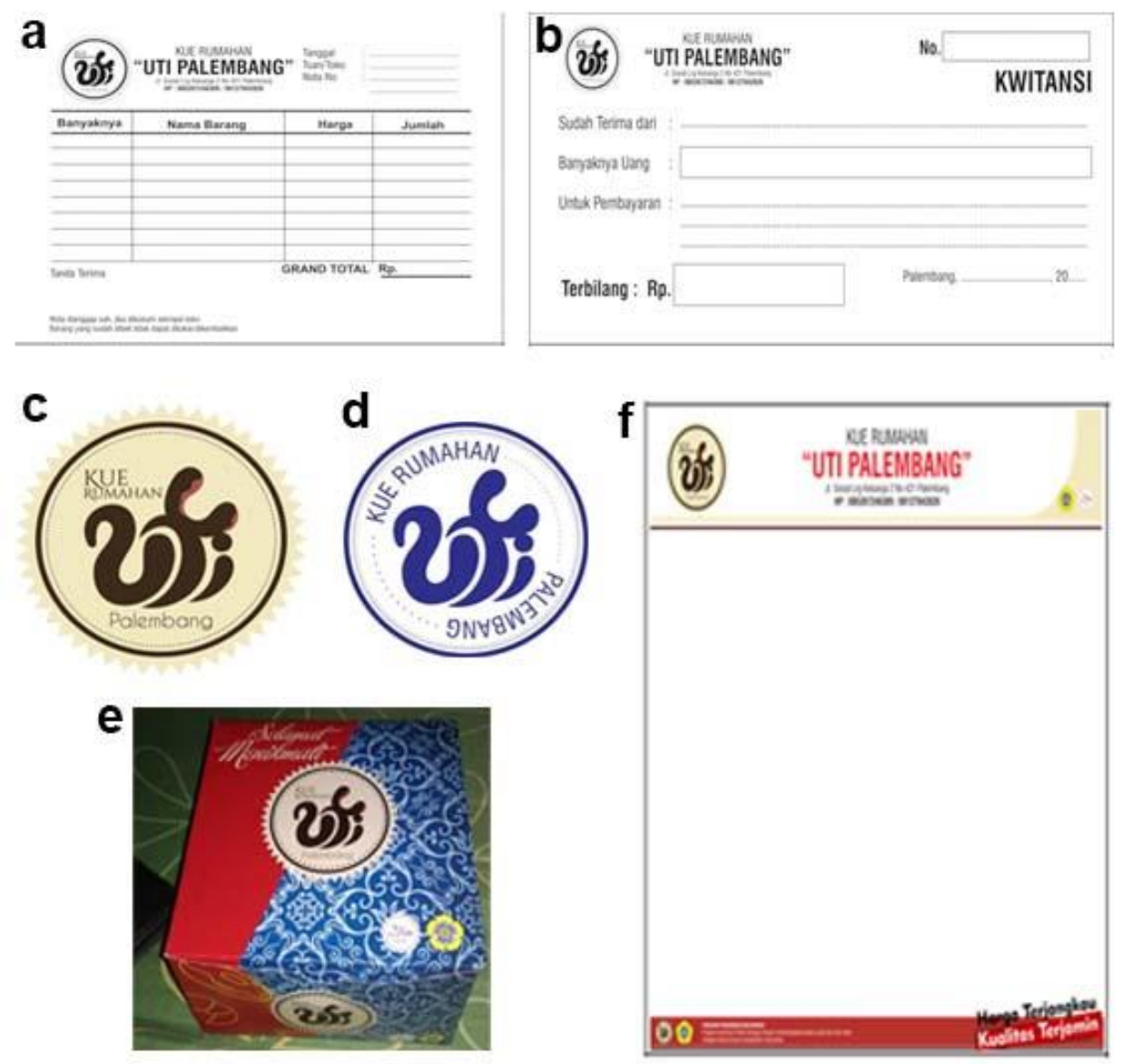

Gambar 3. Dokumen Bisnis dan Desain Kemasan. (a) Nota; (b) Kuitansi; (c) Logo; (d) Stempel; (e) Kemasan/kotak kue; (f) Kop Surat

\section{KESIMPULAN}

Kegiatan Pengabdian Kepada Masyarakat ini membantu Mitra dalam mengembangkan dan mempromosikan usahanya. Mitra dapat memahami tentang marketing mix dan mampu menerapkannya dalam kegiatan usaha yang telah digeluti selama ini. Selain itu dengan adanya dokumen-dokumen bisnis yang disediakan ikut membantu Mitra secara legalitas untuk kegiatan kerjasama dan secara tidak langsung juga ikut membantu mempromosikan produk mitra agar dapat menawarkan produk-produknya kepada perusahaan, lembaga-lembaga, maupun instansi-instansi baik di pemerintahan maupun swasta. Dengan semakin dikenal usaha Mitra dapat menambah omzet dan dapat lebih memperluas usaha Mitra tersebut.

\section{UCAPAN TERIMA KASIH}

Tim pelaksana kegiatan mengucapkan terima kasih kepada Direktur Politeknik Negeri Sriwijaya dan Kepala Unit P3M Politeknik Negeri Sriwijaya yang telah mendukung kegiatan pengabdian ini. Selain itu Tim juga mengucapkan terima kasih kepada mitra yang telah menyediakan waktu dan 
tempat dan dapat bekerja sama sehingga kegiatan pengabdian ini dapat terlaksana sesuai dengan waktu yang telah ditentukan.

\section{DAFTAR PUSTAKA}

Aziz, Roikhan Mochamad, dkk. 2020. Upaya Mingkatkan Motivasi Berwirausaha yang Berbasis Online pada Masyarakat Desa Tanjakan. MATAPPA: Jurnal Pengabdian Kepada Masyarakat. 3(1): 13-19. DOI: http://dx.doi.org/10.31100/matappa.v3i1.497

Finoza, Lamuddin. 2009. Aneka surat Sekretaris dan Bisnis Indonesia. Jakarta: Penerbit Diksi Insan Mulia.

Fitri, Ayu, Budi Rismayadi, Mumun Maemunah. 2020. Pelatihan Kewirausahaan tentang Bisnis Rumahan Bagi Ibu Rumah Tangga Di Desa Rengasdengklok Selatan Kecamatan Rengasdengklok Kab Karawang. BERNAS: Jurnal Pengabdian Kepada Masyarakat. 1(1): 2231. DOI: https://doi.org/10.31949/jb.v1i1.117

Kotler, Philip dan Gary Armstrong. 2012. Prinsip-prinsip Pemasaran (Edisi 13. Jilid 1). Jakarta: Erlangga.

Kotler, Philip dan Kevi Lane Keller. 2009. Manajemen Pemasaran (Jilid I, Edisi ke 13). Jakarta: Erlangga.

Widiatuti, Tri, dkk. 2018. Peningkatan Kesejahteraan Keluarga Melalui Pelatihan Wirausaha Produk Camilan Sehat Stik Sea Food bagi Ibu Rumah Tangga di Kelurahan Mlatibaru Semarang. Journal of Dedicators Community (JDC). 2(1): 17-26. DOI: 10.34001/jdc.v2i1.682 